\title{
Thermomechanical Analysis of a Reactor Pressure Vessel under Pressurized Thermal Shock Caused by Inadvertent Actuation of the Safety Injection System
}

\author{
M. Annor-Nyarko $\mathbb{D}^{1,2,3}$ Hong Xia $\mathbb{D}^{1,2}$ and Abiodun Ayodeji ${ }^{4}{ }^{4}$ \\ ${ }^{1}$ Key Laboratory of Nuclear Safety and Advanced Nuclear Energy Technology, Ministry of Industry and Information Technology, \\ Harbin Engineering University, Harbin 150001, China \\ ${ }^{2}$ Fundamental Science on Nuclear Safety and Simulation Technology Laboratory, Harbin Engineering University, \\ Harbin 150001, China \\ ${ }^{3}$ Nuclear Installations Directorate, Nuclear Regulatory Authority, Accra, Ghana \\ ${ }^{4}$ State Key Laboratory of Industrial Control Technology, Control Department, Zhejiang University, Hangzhou 310027, China
}

Correspondence should be addressed to Hong Xia; xiahong@hrbeu.edu.cn

Received 9 November 2021; Revised 21 December 2021; Accepted 23 December 2021; Published 2 February 2022

Academic Editor: George Bakos

Copyright $\odot 2022$ M. Annor-Nyarko et al. This is an open access article distributed under the Creative Commons Attribution License, which permits unrestricted use, distribution, and reproduction in any medium, provided the original work is properly cited.

\begin{abstract}
The damage induced pressurized thermal shock (PTS) may pose to a reactor pressure vessel (RPV) is a critical safety requirement assessed as part of the ageing management programme of pressurized water reactors (PWRs). A number of researches have studied PTS initiated mainly by postulated accidents such as loss of coolant accidents (LOCAs). However, investigations on PTSinduced threat on RPV caused by inadvertent actuation of the safety injection, a frequent anticipated transient, have not been thoroughly studied. In this paper, a simplified multistep analysis method is applied to study the thermomechanical status of a twoloop PWR under PTS loads caused by inadvertent actuation of the safety injection system. A direct-coupling thermomechanical analysis is performed using a three-dimensional (3D) RPV finite element model. A 3D finite element submodel (consisting of the highiest stress concentration area in the RPV) and an assumed crack are then used to perform fracture mechanics analysis. Subsequently, the critical integrity parameter-stress intensity factor (SIF) is estimated based on FRANC3D-M-integral method coupled in the multistep simulation. The material fracture toughness of the vessel is computed based on the master curve method with experimental fracture toughness data. The results obtained from the direct coupling stress analysis in comparison with sequential coupling approach demonstrate the effectiveness of the proposed multistep method. Also, comparing SIF results obtained with that calculated based on the conventional virtual crack-closure technique (VCCT) and extended finite element method (XFEM) show good agreement. This study provides a useful basis for future studies on anticipated transient-induced crack propagation and remaining service life prediction of ageing reactor pressure vessels.
\end{abstract}

\section{Introduction}

The reactor pressure vessel (RPV), a critical component of a pressurized power reactor (PWR), is subjected to high temperature, high pressure, and fast neutrons emitted from the heat-generating core during its operations [1]. A key safety principle in the operations of an ageing PWR is to maintain the safety margins of the nonreplaceable RPV [2]. Furthermore, a critical-size defect in a vessel with a significant loss in ductility can grow rapidly under some reactor operating conditions leading to damage or, in severe cases, failure. Thus, thermomechanical characteristic analysis of critical equipment such as PWR's vessel subjected to transient cyclic loads from postulated accidents (PA), anticipated transients (AT), or beyond design base accidents (DBA) is vital to ensure the long-term operations of the reactor. In addition, these vessel safety analysis results guide reactor utilities on the relevant inputs for the development of ageing management programmes that may avert potential damage or severe catastrophes. 
A potential threat to the safety of ageing nuclear power reactors is the exposure of its vessel to PTS cyclic loads caused by the temperature gradient and internal pressure of a PA, AT, or DBA [3]. An anticipated transient (condition II event) under no reactor operating conditions should build up to postulated or beyond design base accidents (condition III or IV event). AT incidents, specifically, the unintentional actuation of safety injection system or reactor makeup system (RMS), mostly occur in PWR NPP. This incident comprises the fill-up of the PWR pressurizer (PZR) and consecutive release of the water via relief valves or safety valves in the PWR [4]. Furthermore, the PWR PZR fill-up can be triggered by water mass addition or a heat-up anticipated transient. In the event of a water mass addition, such as inadvertent opening of a pressurizer relief valve, inadvertent actuation of the emergency core cooling system (ECCS), or malfunction of a chemical and volume control system, the turned-on plant will not halt the water flow from the ECCS into the reactor cooling system. The PZR level will still rise till a reactor operator stops the injection water flow before hitting a more severe condition III event or it reaches a water solid pressurizer condition [4-6]. As stated in open literature, a small break loss of coolant accident (SBLOCA) condition II event, caused by inadvertent operation of the ECCS, an anticipated transient, has a higher likelihood of occurrence in a reactor plant compared to condition III SBLOCA [6]. Similarly, Niffenegger et al. after a thermalhydraulic screening investigation stated that the inadvertent opening of a PZR relief valve generates significant PTS due to its frequent occurrence [7]. Thus, the relative high frequency of anticipated transients during the operational life of a PWR in contrast with the widely investigated loss of coolant postulated accidents can have a long-term negative effect on the thermomechanical characteristics of the pressure vessel [4].

Several scenarios adopted in the numerical studies of the thermomechanical status of a reactor pressure vessel under PTS loadings are typically based on loss of coolant postulated accidents [3]. Also, the thermomechanical coupling method applied mostly followed a sequential approach. Fekete T. has reviewed the prospect of modern thermomechanics in structural integrity calculations of pressure vessels [8]. Chouhan R. et al. have also presented computational studies on pressurized thermal shock in an RPV [9]. The integrity analyses of a reactor pressure vessel under PA PTS scenarios using the TRACE-XFEM approach have been performed by Mora D. F. et al. [10]. Also, Mora D. F. et al. have modeled a reactor pressure vessel subjected to pressurized thermal shock using 3D-XFEM [11]. However, investigations on the thermomechanical characteristic change of an RPV's steel under PTS from anticipated transients are rarely studied, in spite of ATs relatively high occurrence in NPP operations $[4,12,13]$. Also, the computational cost-effective direct coupling method has not been applied in the analyses of the thermomechanical state of RPV of PWRs during PTS transient. Furthermore, nuclear safety statutes or regulations obligate NPP utilities to evaluate all likely anticipated and accidental emergency events as key aspects of the structural integrity assessment and approvals of reactor license extension applications $[5,14]$.
It is worth noting that the frequent inadvertent injection of emergent coolant from the SIS during reactor operations can induce high thermal stress in areas of the PWR vessel in contact with the coolant [15]. These induced stresses in combination with the RPV's high inner pressure may cause ageing mechanism defects to grow leading to damage or severe failures $[16,17]$. Thus, a comprehensive safety evaluation of ageing PWRs must consist of the thermomechanical characteristics analysis of RPV under PTS cyclic loadings caused by probable anticipated transients and postulated accidental events. This is an essential part of the regulatory process for a reactor's service life extension and ageing management programme.

Thus, this study presents a simplified multistep approach to analyse the thermomechanical characteristics status of a twoloop PWR pressure vessel subjected to PTS cyclic loads induced by an inadvertent actuation of a safety injection system. Firstly, a direct thermomechanical coupling-simulation method is proposed to estimate the maximum thermomechanical stress area in a three-dimensional finite element RPV model (3D-FE) created in Abaqus software. A 3D numerical submodeling method is then used to calculate the integrity parameter-stress intensity factor $\left(K_{I}\right)$ of an assumed axial oriented semielliptical crack set in a $3 \mathrm{D}$-FE submodel. Next, $K_{I}$ at the deepest crack point is calculated based on the M-integral method coupled in the proposed multistep process implemented in fracture analysis code-3D (FRANC3D). $K_{I}$ is also estimated using the conventional virtual crack-closure technique (VCCT) and extended finite method (XFEM) to ascertain the accuracy of our proposed method. Lastly, $K_{I}$ is compared with the RPV's material fracture toughness master curve $\left(K_{I C}\right)$ estimated from experimental fracture toughness test data to determine the potential damage a frequent anticipated transient may pose on an ageing reactor pressure vessel. The innovations in this study are summarized as follows:

(1) The work proposes a simplified multistep analysis method to evaluate the thermomechanical characteristic risk posed by the most recurrent anticipated transient (inadvertent actuation of a safety injection system) on a RPV steel. This method provides simpler computational steps in the numerical simulation of the integrity parameter-stress intensity factors in the safety assessment of complex reactor structures.

(2) The work presents a direct coupling-simulation approach that simultaneously computes the thermal and internal pressure loads in the estimation of the thermomechanical stress concentration in a vessel FE model. This approach reduces the simulation cost and runtime in computing stresses compared with the conventional sequential coupling method.

(3) The $K_{I C}$ estimated using the master curve approach with a multitemperature method and experimental fracture toughness test data limited the overconservatism in the computation of ageing RPV's steel toughness. The critical parameter, $K_{I}$, calculated using the FRANC3D-M-integral approach also 
agrees with both the conventional XFEM approach and VCCT, confirming the accuracy of the multistep analysis method.

(4) This study serves as a reference for computing the thermomechanical characteristic changes other anticipated transients may have on the steel material of an ageing reactor pressure vessel.

\section{Background}

2.1. Safety Injection System Analysis and Reference Anticipated Transient. The safety injection system (SIS) is a primary safety-related component in a reactor that causes the injection of cooling water in the reactor coolant system (RCS) following a loss of coolant accident (LOCA). A typical PWR's SIS consists of four pumps classified as high-pressure safety injection (HPSI) pumps. Two inlets pumps of the SIS are linked through power-operated isolation valves to a refueling water storage tank (RWST). Furthermore, the shutdown margin pump's outlets are connected to the inlets of the two HPSI pumps. These pump outlets are linked to a pipe header with discharge channels connected to the cold or hot legs of the coolant system. Following the operation of the injection system, the high-pressure pumps cause the cooling water from the RWST to be released into the core of the reactor [18]. Transient incidents that cause the unintentional injection of cooling water directly into the RPV's downcomer give rise to high pressurizer levels. In addition, the recurrent inadvertent actuation of the SIS during the operational service life of PWR either by a reactor operator error or by a control system misfunction may induce high thermal stresses in the nozzles or inner vessel wall $[4,5]$.

2.2. PWR Reactor Pressure Vessel Model. The main parameters of the adopted PWR design in this study are presented in Table 1. The referenced PWR's RPV (Figure 1(a)) is built to withstand high temperature, high pressure, corrosion, and the detriments associated with fast neutron irradiation exposure during the PWR's operational lifetime. The core beltline, closure head to flange juncture, lower shell to bottom head transition, and connecting inlet nozzles are classified as critical sections of the vessel. Furthermore, these sections are susceptible to high thermal stresses and the likelihood of crack initiation [19]. Thus, a three-dimensional (3D) model consisting of $1 / 2$ of a typical two-loop PWR RPV design, without cladding material, shown in Figure 1 (b)is assumed for this study. The vessel's internal diameter, vessel wall thickness, and the diameter of the inlet nozzle are $3,374 \mathrm{~mm}, 170 \mathrm{~mm}$, and $700 \mathrm{~mm}$, respectively. Also, the finite element (FE) model of the RPV presented in Figure 1(c) is used for the direct thermomechanical coupling analysis part of the proposed simplified multistep simulations. The symmetricity boundary condition is applied. Also, the upper section of the numerical model is left in a free state whereas the bottom section is restrained against any displacement of the model. The whole FE model is preprocessed and fine-meshed in HyperMesh software [20].
TABLE 1: The main parameters of the referenced PWR.

\begin{tabular}{lc}
\hline Parameters & Value \\
\hline Reactor type & 2-loop PWR \\
Design pressure & $17.2 \mathrm{MPa}$ \\
Normal operating pressure & $15.2 \mathrm{MPa}$ \\
Hydrostatic test pressure & $21.5 \mathrm{MPa}$ \\
Design temperature & $350^{\circ} \mathrm{C}$ \\
Normal operating inlet temperature & $288.8^{\circ} \mathrm{C}$ \\
Normal operating outlet temperature & $315.2^{\circ} \mathrm{C}$ \\
Design life & 30 years \\
\hline
\end{tabular}

2.3. RPV Steel Properties. The RPV is manufactured from low-alloy ferritic steel, SA508 Class 3 . Table 2 presents the key properties such as thermal conductivity $(\lambda)$, elastic modulus (E), coefficient of thermal expansion $(\alpha)$, and specific heat capacity $(C)$ of the RPV steel [11]. In addition, density, Poisson's ratio, and the vessel's material yield strength at room temperature are $7,600 \mathrm{kgm}^{-3}, 0.3$, and $450 \mathrm{MPa}$, respectively, as stated in $[11,21]$. Furthermore, the coefficients of thermal expansion are converted to the stressfree reference temperature of $289^{\circ} \mathrm{C}$ based on the procedure proposed by M. Niffenegger et al. [22].

2.4. Master Curve Material Fracture Toughness. Ageing RPV experiences a reduction in material toughness and nil-ductility transition temperature upward shift due to the bombarded of high-energy neutrons from the reactor core [5]. The master curve (MC) approach is applied in this study to evaluate the fracture toughness of the selected vessel material $\left(K_{I C}\right)$ [23].

The MC cumulative failure probability based on a threeparameter Weibull model for a temperature data range is expressed as follows:

$$
P_{\mathrm{cf}}=1-\exp \left[-\frac{B}{B_{0}}\left(\frac{K_{I C}-20}{K_{0}-20}\right)^{4}\right],
$$

where $P_{\mathrm{cf}}, B_{0}, B, K_{I C}$, and $K_{0}$ are the cumulative failure probability, referenced specimen thickness, nominal specimen thickness, vessel's material toughness, and the Weibull scale parameter at a toughness value of $P_{\mathrm{cf}}=63.2 \%$, respectively. The computation of the MC transition temperature follows the conversion of fracture toughness of different size specimen data to the standard fracture toughness [23]. All specimen thicknesses are adjusted to the reference specimen thickness $(25 \mathrm{~mm})$ using the following equation:

$$
K_{I C(I T)}=20+\left(K_{I C(x)}-20\right)\left(\frac{B}{B_{I T}}\right)^{0.25} .
$$

The scale parameter, $K_{0}$, is estimated using the following equation:

$$
K_{0}=\sum_{i=1}^{N}\left[\frac{\left(K_{I C(i)}-20\right)^{4}}{r}\right]^{1 / 4}+20,
$$

where $i, r$, and $N$ are the fracture toughness sequence number, number of uncensored data, and the total number 


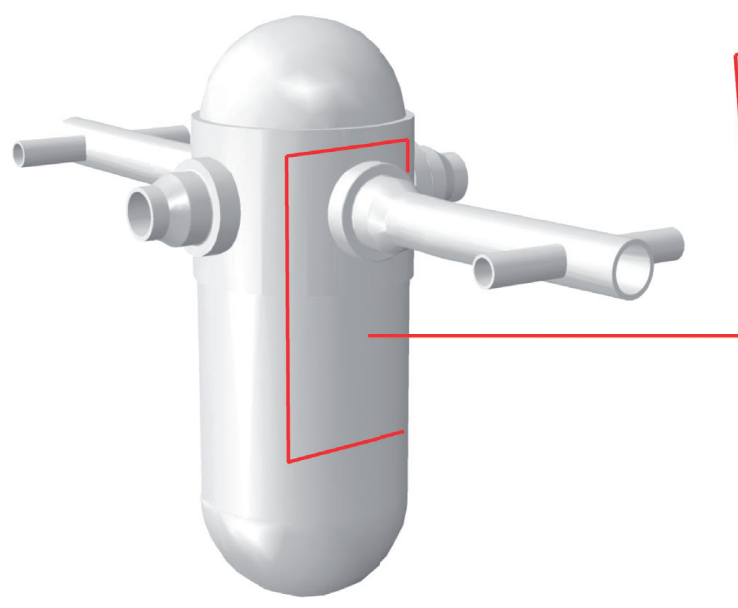

(a)

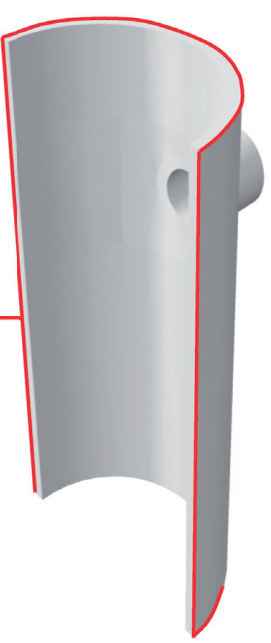

(b)

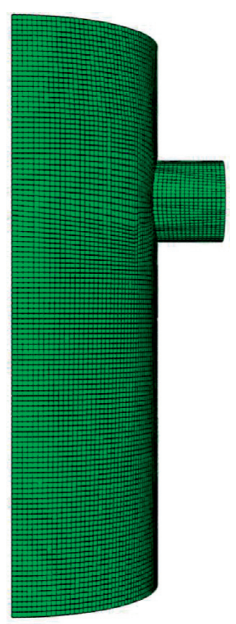

(c)

Figure 1: (a) Geometry of RPV, (b) simplified RPV model, and (c) finite element meshed model.

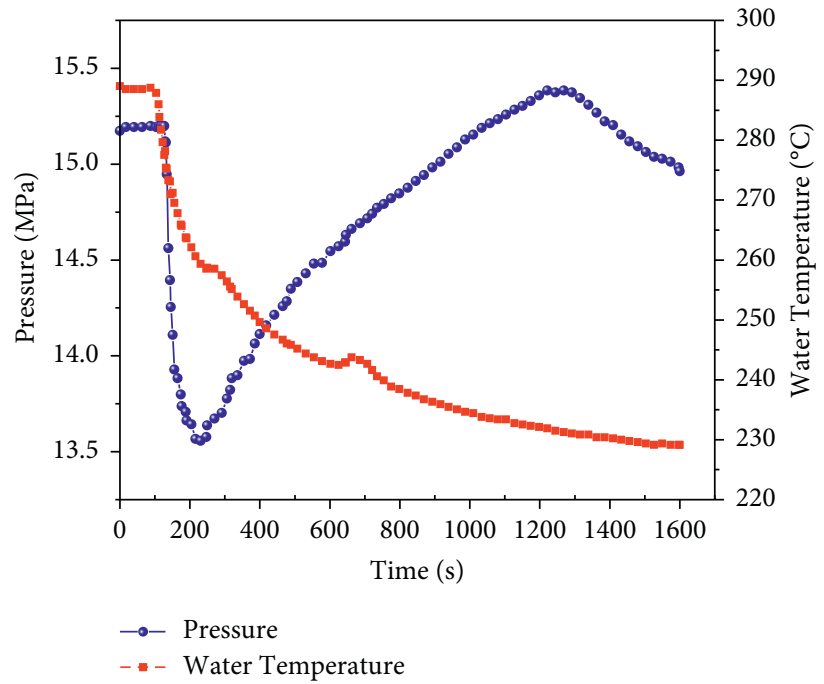

Figure 2: The temperature and pressure histories during PTS transient event.

of fracture toughness test data, respectively. Also, the $K_{0}$ parameter at different temperatures of ferritic steels may be expressed as follows:

$$
K_{0}=\omega+\tau \exp \left[\gamma\left(T-T_{0}\right)\right]
$$

where $\gamma$ is a material constant and $\omega$ and $\tau$ are correlation coefficients, and $\omega+\tau=108$. From experimental studies, the shape of the toughness curve versus temperature is only dependent on the yield strength and type of steel material. Hence, $\gamma, \omega$, and $\tau$ in equation (4) are highly independent of the categories of steel $[21,24]$. Equation (4) is approximated as represented in the following equation through the comparison of a wide range of ferritic steel data from open literature $[24,25]$ :

$$
K_{0}=31+77 \exp \left[0.019\left(T-T_{0}\right)\right]
$$

Substituting equation (5) into equation (1), the mean fracture toughness that corresponds to a $50 \%$ probability of failure, at different temperatures $(T)$, is expressed as follows:

$$
K_{I C}(\mathrm{med})=30+70 \exp \left[0.019\left(T-T_{0}\right)\right],
$$

where $K_{I C}$ (med) is the median fracture toughness and $T_{0}$ is the transition temperature at which a median probability $\left(P_{\mathrm{cf}}=0.5\right)$ fracture toughness $\left(K_{I C}\right)$ of $100 \mathrm{MPam}^{0.5}$ would be obtained from a $25 \mathrm{~mm}$ thick specimen. Also, the ASME material fracture toughness (IWB-3613) for the inlet nozzlevessel empirical formula is expressed as follows [5]:

$$
K_{I C v}=25.81+16.11 \exp [0.019(T-79.7)] .
$$

$T_{0}$, the RPV material's macro fracture state characterization parameter, is calculated based on an ASTM standard E1921-05 multitemperature iteration method using the 
material fracture toughness test data referenced RPV reported in open literature $[24,26,27]$ as follows:

$$
\begin{aligned}
& \sum_{i=1}^{N} \frac{\delta_{i} \exp \left[0.019\left(T_{i}-T_{0}\right)\right]}{11+77 \exp \left[0.019\left(T_{i}-T_{0}\right)\right]} \\
& -\sum_{i=1}^{N} \frac{\left(K_{I C(i)}-20\right)^{4} \exp \left[0.019\left(T_{i}-T_{0}\right)\right]}{\left\{11+77 \exp \left[0.019\left(T_{i}-T_{0}\right)\right]\right\}^{5}}=0,
\end{aligned}
$$

where $T_{i}$ is the test temperature corresponding to $K_{I C(i)}$ and $\delta_{i}$ is the censoring parameter [25]. The $K_{I C}$ values at different temperatures and RPV material failure probabilities are computed using the following equation:

$$
K_{I C}\left(P_{\mathrm{cf}}\right)=20+\left[-\ln \left(1-P_{c}\right)^{0.25}\right]\left[11+77 \exp \left(0.019\left(T-T_{0}\right)\right)\right]\left(\frac{B_{I T}}{B}\right)^{0.25}
$$

In this study, the $T_{0}$ conservatively estimated corresponds to the inner RPV's surface fracture toughness without the consideration of fast nonhomogeneous neutron irradiation through the vessel wall thickness. 0.5T-CT specimens were used in the experimental fracture toughness test data investigations selected from open literature [26].

\section{Analysis Method}

3.1. Reference Anticipated Transient Event and Multistep Cosimulation Implementation. The inadvertent actuation of the SIS PTS transient loads used in this paper was determined by Wang et al. [18]. This kind of anticipated transient incident often occurred during the service life of PWRs and records of these events are documented in several IAEA reactor operating experience feedback reports $[13,28]$. The unanticipated actuation of the SIS caused the pumping of cooling water into the coolant system creating a surge in the RCS pressure. The highest injection flow rate of the cooling water recorded was $13 \mathrm{~kg} / \mathrm{s}$. Figure 2 presents the temperature of the coolant and inner pressure variations estimated from the referenced PTS anticipated transient. The initial temperatures of the inside and outside vessel surfaces are conservatively assumed as $289^{\circ} \mathrm{C}$ and $20^{\circ} \mathrm{C}$, respectively. Between the ambient air and the outside vessel wall, the heat transfer coefficient $(h)$ is taken as $20 \mathrm{~W} / \mathrm{m}^{2 \circ} \mathrm{C}$. The direct thermomechanical analysis was performed following the multistep simulation procedure shown in Figure 3.

\subsection{Fluid-to-RPV Wall Heat Transfer Coefficient Estimation.} The mathematical relation used for the approximation of the heat transfer coefficient $(h)$ arising from heat transferred from the cooling water injected to the internal vessel surface is given as follows [29, 30]:

$$
h=\frac{N_{u} k}{D}
$$

where $N_{u}, k, h$, and $D$ are the Nusselt number, thermal conductivity of water, heat transfer coefficient, and hydraulic diameter, respectively (the hot leg diameter of $0.699 \mathrm{~m}$ is assumed in the FER PV model for this study).
The Nusselt number is determined using the following equation:

$$
N_{u}=C(\mathrm{GrPr})^{n}
$$

where $\mathrm{Gr}$ and Pr are Grashof and Prandtl numbers, respectively [29]. Hence, the heat transfer coefficient is given as follows:

$$
h=C k\left(\frac{D^{2} \rho^{2} g \beta \Delta T}{\mu^{2}} \operatorname{Pr}\right)^{n},
$$

where $g, \Delta T, \mu, \rho$, and $\beta$ are the gravity, temperature change, viscosity, density, and isobaric cubic expansion coefficient, respectively [31, 32]. $k, n$, and $C$ are taken as $0.6096 \mathrm{~W} / \mathrm{m} \mathrm{K}$, 0.3 , and 0.590 , respectively. The physical properties $\beta$, $C_{p}, g, \rho$, and $\mu$ values assumed in this study were determined at $\triangle T=289^{\circ} \mathrm{C}$ and PWR pressure $=14.7 \mathrm{MPa}$ using the STEAMEST tool created by M. Faheem et.al [31].

3.3. Direct Thermomechanical Model. A direct thermomechanical coupling analysis was carried out using the FE model of the RPV shown in Figure 4(a). The FE model consists of the steel material thermomechanical properties (Table 2) coupled with the assumed boundary conditions stated in Section 3.1. Also, the model was finely discretized using eight-node mesh element type C3D8T. The mesh type was created using HyperMesh, a finite element pre-processor tool. The heat transfer coefficient between the outside vessel wall and ambient air is set at $20 \mathrm{~W} / \mathrm{m}^{2 \circ} \mathrm{C}$. The temperature of the outside vessel wall was assumed to be $20^{\circ} \mathrm{C}$. The pressure and temperature distributions estimated during the PTS anticipated transient (Figure 2) and $h=8,450 \mathrm{~W} / \mathrm{m}^{2 \circ} \mathrm{C}$, determined using equation (12), were taken as the loadings and input for the simulation. The assumed boundary conditions and loadings were applied in the $3 \mathrm{D}-\mathrm{FE}$ model as presented in Figure 4(a). This was then used in the Abaqus commercial tool to compute the corresponding thermomechanical stresses.

3.4. Fracture Mechanics Node-Based Submodel. Leakages or, in severe cases, failures likely to occur in reactor pressure vessels are mostly initiated from shallow surface defects [33]. 


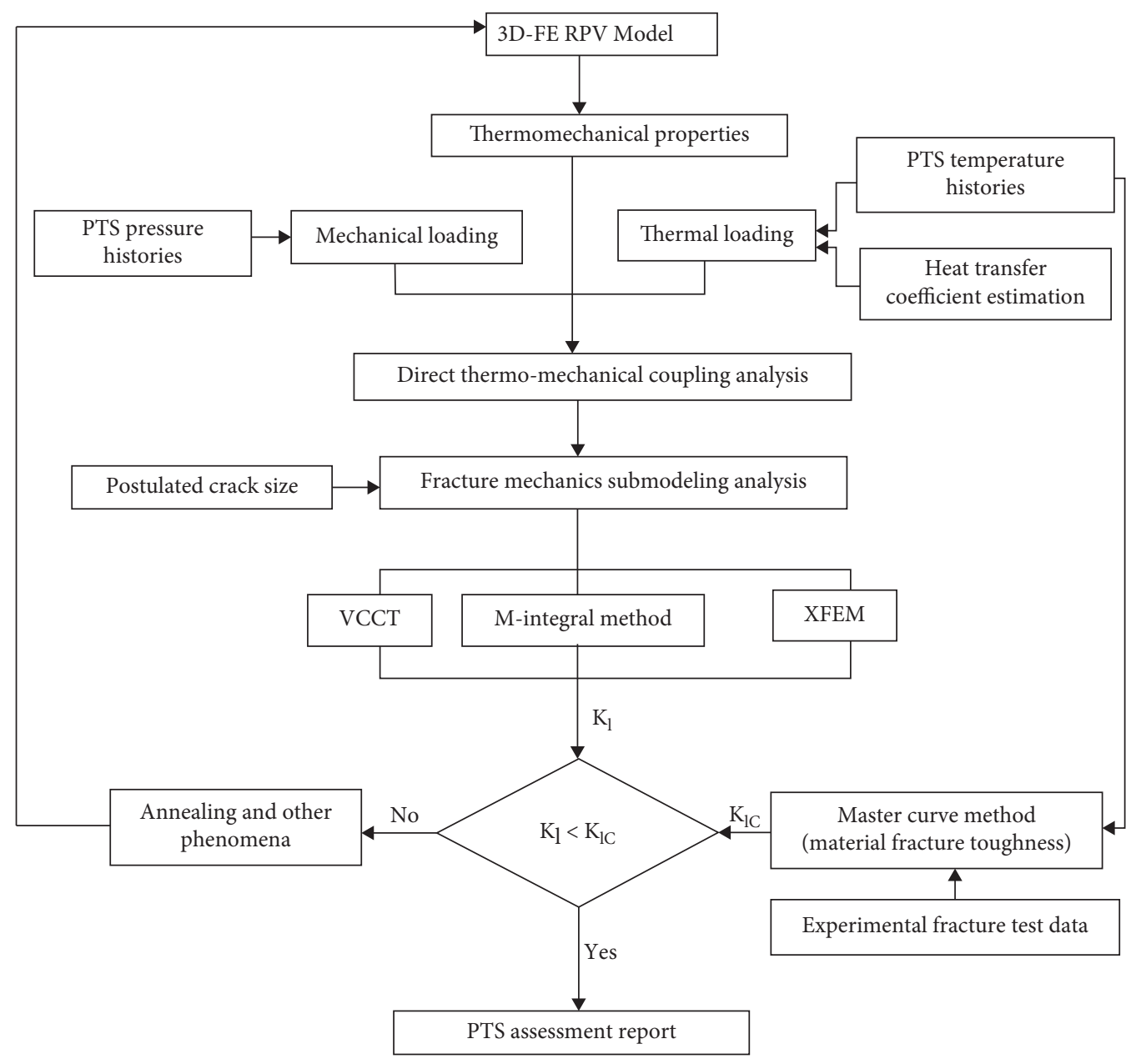

FIGURe 3: Flow diagram of the multistep analysis of RPV under PTS transient loadings.

Furthermore, probabilistic fracture mechanics analyses performed and presented in open literature show that shallow cracks compared with deep cracks contribute more to the likelihood of crack initiation in RPV. This is due to the severity of the thermomechanical loadings and neutron irradiation exposure at the RPV inner surface [15]. An axial semielliptical surface crack geometry of a depth (a) of $1 / 4$ the $\mathrm{RPV}$ wall thickness with an aspect ratio $(a / 2 c)=(1 / 6)$ is assumed for this fracture modeling [34]. This postulated surface crack size is mostly seen in the nondestructive testing of ageing RPV materials $[5,35]$. The finite element submodel presented in Figure 4(b), which contains the maximum stress concentration area created from the results of the direct thermomechanical simulation (Figure 5), was finemeshed (Figures 6 and 7) for the stress intensity factor calculations $\left(K_{I}\right)$. The critical parameter, $K_{I}$, was estimated following the conventional linear elastic fracture mechanics method (LEFM). The numerical submodels integrated boundary conditions of the global RPV model as presented in Figure 4(b), through the incorporation of the extracted temporal displacements as mechanical boundary conditions at the submodel's edges during the analysis process. The $K_{I}$ values were calculated as a function of the postulated crack size/direction and the thermomechanical stress variation using the superposition principle. The parameter, $K_{I}$, was computed at the deepest point of the crack front by the FRANC3D-M-integral approach coupled in the multistep simulation proposed, extended finite element method (XFEM), and VCCT (virtual crack-closure technique). Finite element finer meshes were created around the postulated crack front in the submodels so as to improve the accuracy of $K_{I}$. A comprehensive study on the computation of stress intensity factors based on the M-integral method is presented in [36]. Publications on VCCT and XFEM methods in the evaluations of $K_{I}$ are also presented in [37-39].

\section{Results and Discussion}

4.1. Direct Thermomechanical Analysis. The direct thermomechanical coupling simulation using the numerical model and assumed boundary conditions defined in Section 3.3 was executed in Abaqus commercial software following the simplified multistep simulation procedure shown in Figure 3. The direct simulation process computed the thermomechanical stresses by the simultaneous coupling of the thermal and pressure loads of the selected PTS transient (Figure 2). This modeling and simulation were to estimate the highest stress concentration area in the FE 


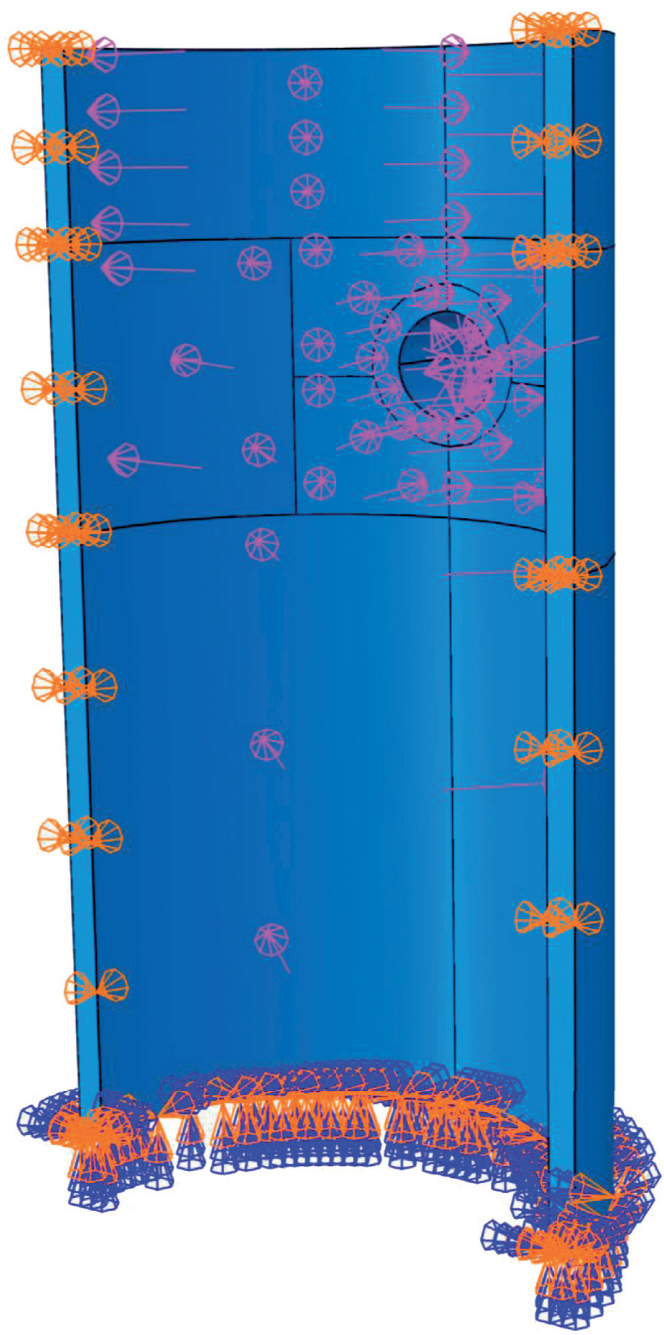

(a)

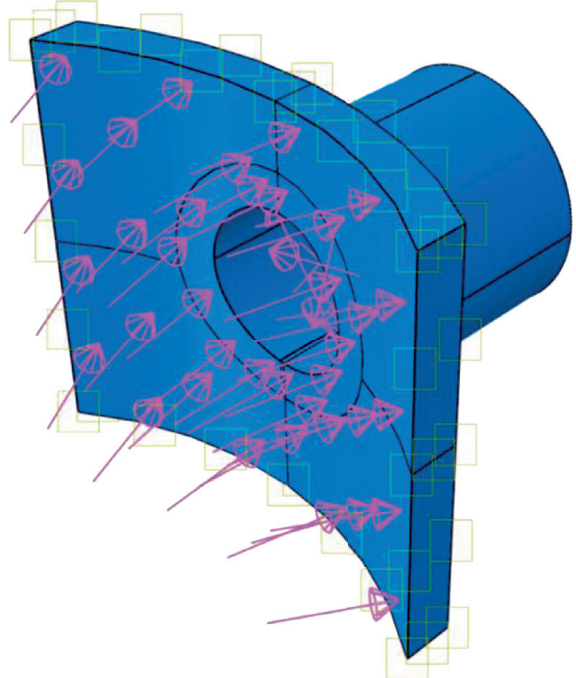

(b)

FIGURE 4: (a) FE global model of the RPV with applied boundary conditions, thermal, and pressure loadings and (b) RPV submodel.

TABLE 2: Thermomechanical properties of the RPV steel material.

\begin{tabular}{lcccc}
\hline $\begin{array}{l}T \\
\left({ }^{\circ} \mathrm{C}\right)\end{array}$ & $\begin{array}{c}\lambda \\
\left(\mathrm{W} / \mathrm{m}{ }^{\circ} \mathrm{C}\right)\end{array}$ & $\begin{array}{c}E \\
(\mathrm{GPa})\end{array}$ & $\begin{array}{c}\alpha \\
\left(10^{-6} 1 /{ }^{\circ} \mathrm{C}\right)\end{array}$ & $\begin{array}{c}\mathrm{C} \\
\left(10^{6} \mathrm{~J} / \mathrm{m}^{3}{ }^{\circ} \mathrm{C}\right)\end{array}$ \\
\hline 50 & 38.3 & 191 & 13.8 & 465.8 \\
100 & 38.8 & 187 & 14.2 & 489.0 \\
150 & 38.8 & 184 & 14.7 & 508.4 \\
200 & 38.6 & 181 & 15.5 & 527.7 \\
250 & 38.1 & 178 & 17.5 & 545.8 \\
300 & 37.5 & 174 & 18.6 & 567.7 \\
350 & 36.8 & 171 & 18.6 & 588.4 \\
\hline
\end{tabular}

model of RPV (Figure 1(c)). Figure 5 shows the von Mises stresses at 1,600 s during the PTS transient. The highlighted area at the inlet nozzle and inside vessel wall intersection (shown in Figure 5) experienced the highest stress value. This was as a result of the complex temperature profile at that stress concentration area. Also, the discontinuity of the inlet nozzle-vessel wall intersection during hydro test and in-service reactor operations create fertile spots for high thermomechanical stresses [14]. Therefore, under a PTS cyclic event, a shallow crack is most probable to be initiated from this location. Figures 8-10 show the temperature, axial, and circumferential stress distributions against different times measured from the highest stress location via the inlet nozzle-inside vessel wall joint (path) thickness. The temperature, axial, and circumferential stresses profiles determined from the highest stress node in the FE model during the PTS transient are presented in Figures 11 and 12. From plots, the temperature profile gradually decreased starting at the inlet nozzle-inner vessel wall intersection through to the outside vessel surface during the entire period of the PTS transient event. The drop in temperature was due to the rapid cooling and large thermal capacity of the RPV steel type. Also, the temperature range of $230^{\circ} \mathrm{C}$ to $270^{\circ} \mathrm{C}$ observed was a result of the high velocity of the coolant pumped out by the high-pressure pumps of the SIS. Furthermore, this temperature range recorded during the anticipated PTS transient event is categorized as relatively high in the operations of power reactors. The 


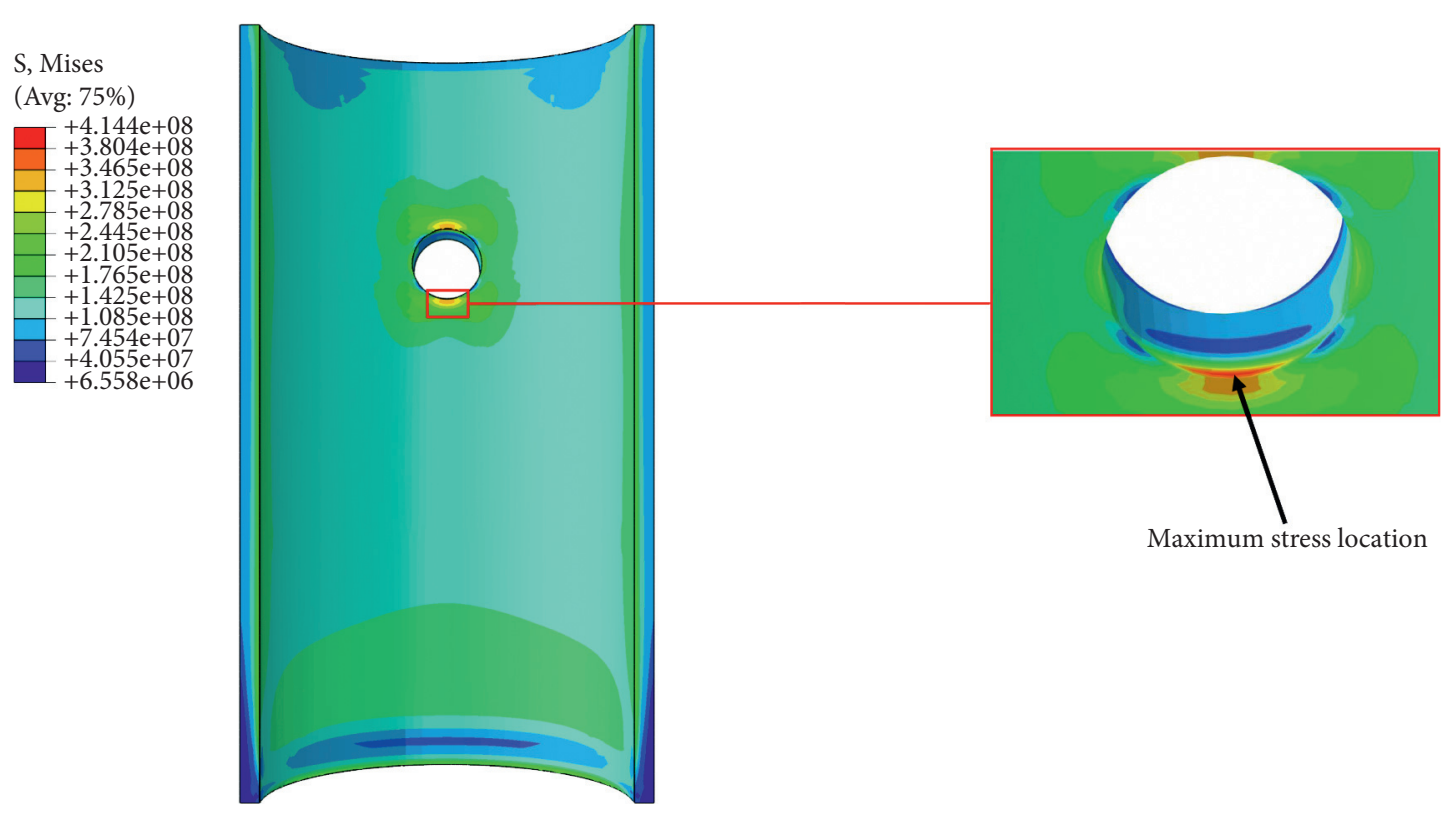

FIGURE 5: Maximum stress concentration area at the inlet nozzle-inside vessel wall intersection of the FE model.

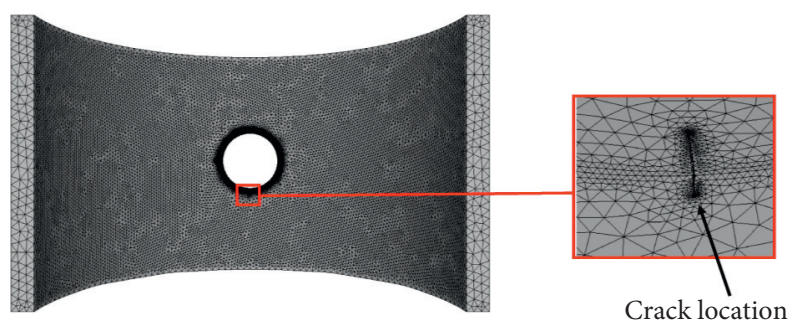

FIGURE 6: RPV submodel with postulated axial semielliptical surface crack created in the FRANC3D tool.

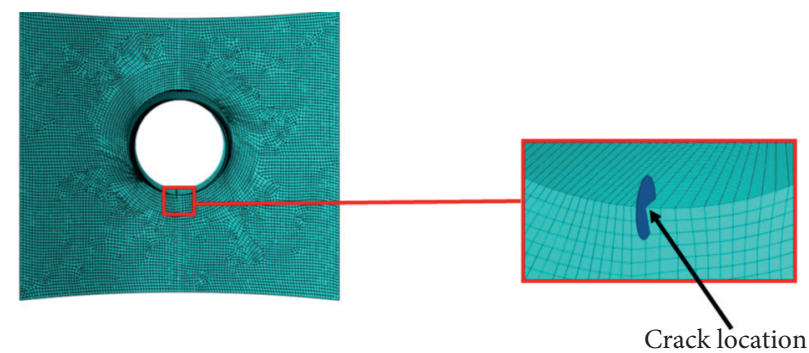

FIGURE 7: RPV submodel with postulated axial semielliptical surface crack created in the Abaqus tool.

circumferential and axial stress profiles decreased from the highest stress point through to a compressive stress value at the vessel's outer surface. The circumferential stress, shown in Figure 12, experienced a steady variation during the first $500 \mathrm{~s}$ of the transient event with a sharp rise at $500 \mathrm{~s}$ before remaining at a uniform value through to the end of the simulation time of $1,600 \mathrm{~s}$. Similarly, the axial stress had a relatively small fluctuation at $500 \mathrm{~s}$ before remaining stable till 1,600 s. These stress distributions displayed were mainly due to the direct coupling simulation of the varied inner pressure and thermal loads during the PTS transient event. Also, the maximum circumferential and axial stresses estimated were below the yield stress of the vessel steel type. Lastly, Figure 13 shows the comparison of the circumferential stress profiles computed based on the proposed direct coupling method (DC) and the conventional sequential coupling approach (SC) performed by Annor-Nyarko M. and Xia H. [5]. The similarity in results obtained confirms the accuracy and effectiveness of the direct coupling approach in the estimation of thermomechanical stresses in RPV models.

4.2. Numerical Fracture Mechanics Analysis. A node-based submodeling technique was used to compute the critical 


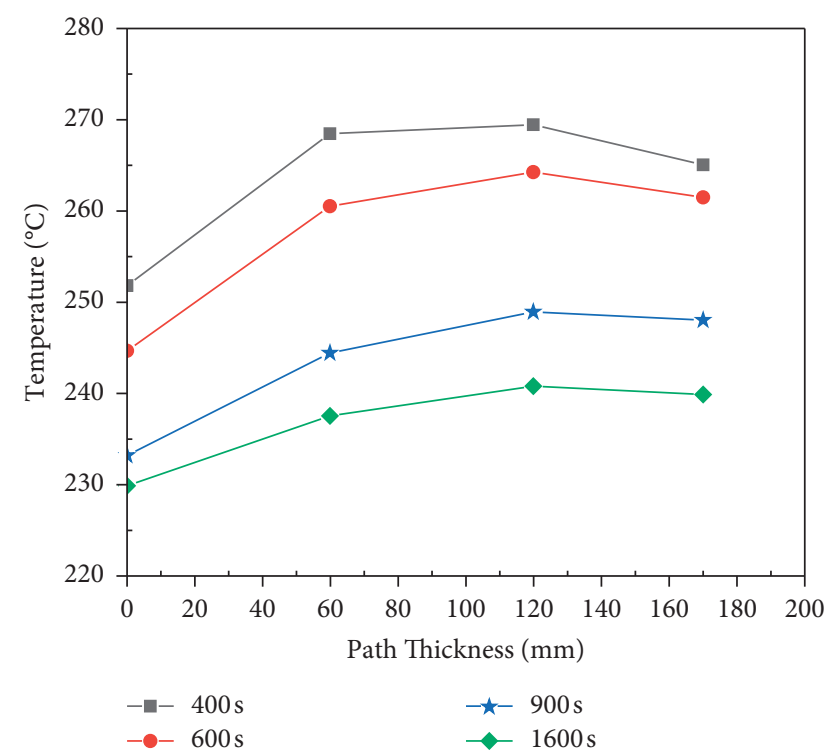

FIgURE 8: Temperature variation along the inlet nozzle-inside vessel wall intersection thickness of the FE model.

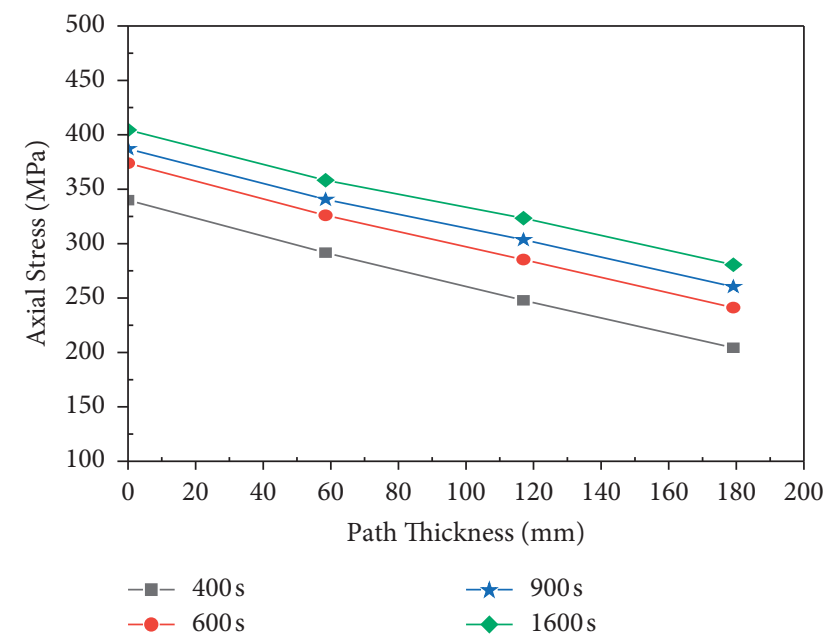

FIGURE 9: Axial stress variation along the inlet nozzle-inside vessel wall intersection thickness of the FE model.

parameter-stress intensity factor $\left(K_{I}\right)$ by creating a submodel from the results of the previous direct thermomechanical stress simulation (Figure 5). The 3D submodels (Figures 6 and 7), which capture the highest stress concentration area, defined in Section 3.4 was developed for the computation of $K_{I}$ following the proposed multistep procedure presented in Figure 3 . The fine mesh type selected for each FE submodel was sensitively tested to ensure runtime efficiency and precision of the $K_{I}$ parameter. An axial-oriented semielliptical crack with a depth of $a=0.042 \mathrm{~m}$ and an aspect ratio of $(a / c)=0.3$ was assumed in the analysis. The postulated surface crack was then inserted at the highest stress concentration spot in the submodels (Figures 6 and 7) created to compute $K_{I}$. These submodels contain the section of the global RPV FE model (Figure 4(a)) that captures the

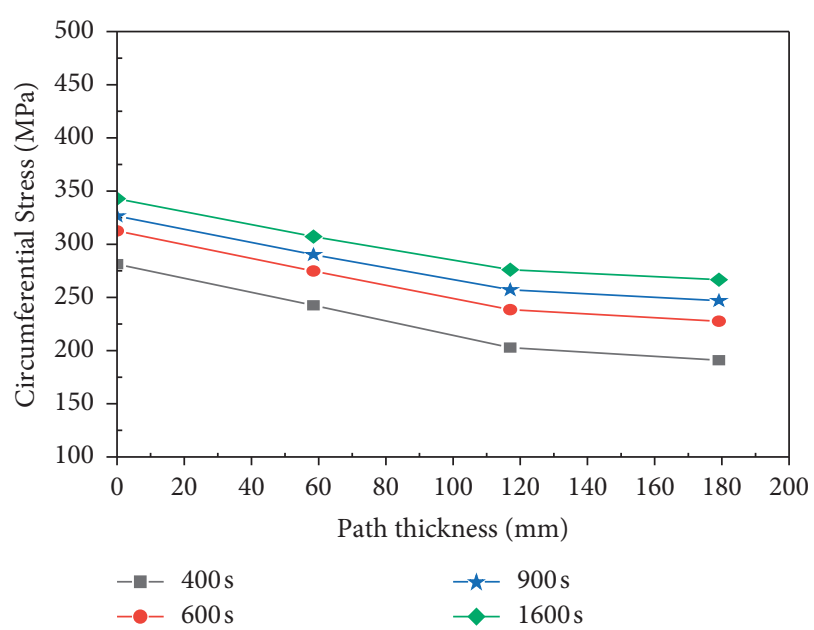

FIgURE 10: Circumferential stress variation along the inlet nozzleinside vessel wall intersection thickness of the FE model.

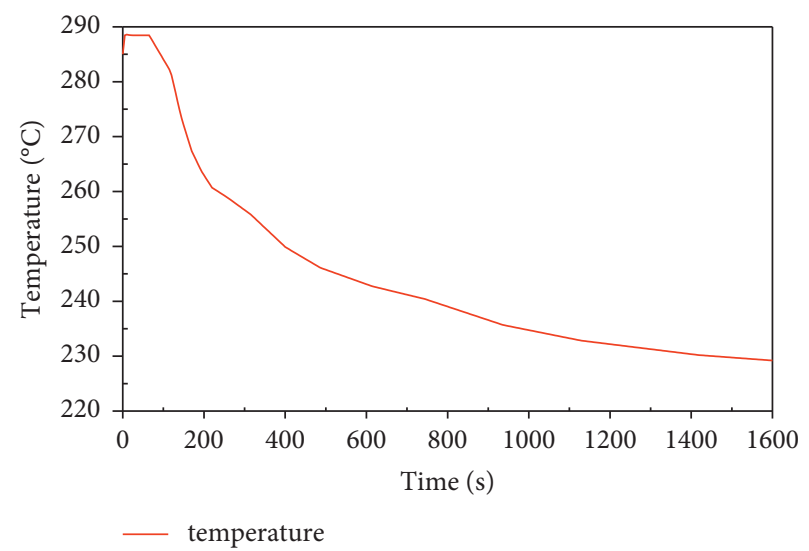

Figure 11: Temperature variation at the maximal stress concentration area in the FE vessel model during the PTS transient.

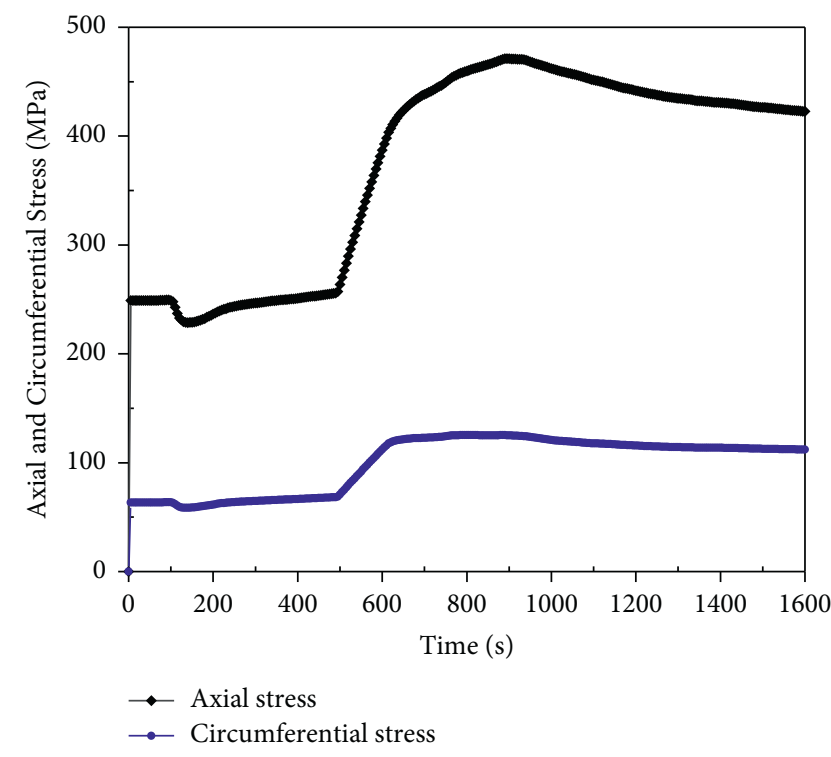

Figure 12: Axial and circumferential stress variation at the maximal stress concentration area in the FE vessel model during the PTS transient. 


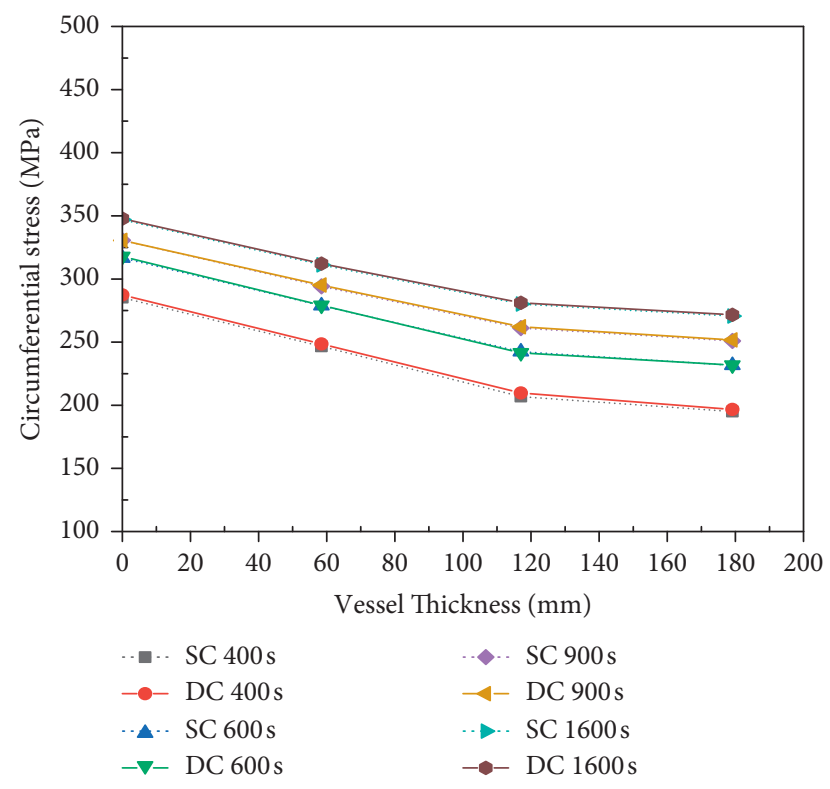

Figure 13: Comparison of circumferential stress estimations from PTS transient based on direct coupling and sequential couplingsimulation methods (SC - sequential-coupling method and DC direct-coupling method).

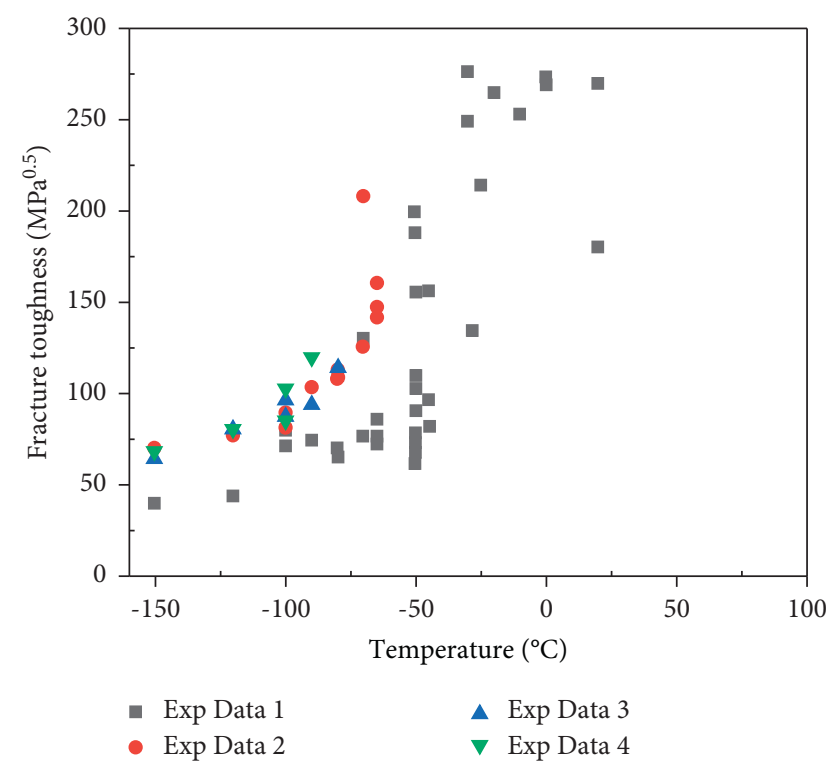

FIGURE 14: Temperature-dependent fracture toughness test data of the referenced RPV steel.

maximum stress concentration area from the preceding stress analysis. Also, the thermal and pressure axisymmetric loadings of the PTS transient and assumed boundary conditions in the submodels were the same as those in the whole FE model as depicted in Figure 4(b).

The stress intensity factors at the deepest point of the crack front were calculated using the FRANC3D-M-integral approach coupled in the simplified multistep couplingsimulation method, VCCT, and XFEM method implemented in Abaqus tool. To accurately compute the linear

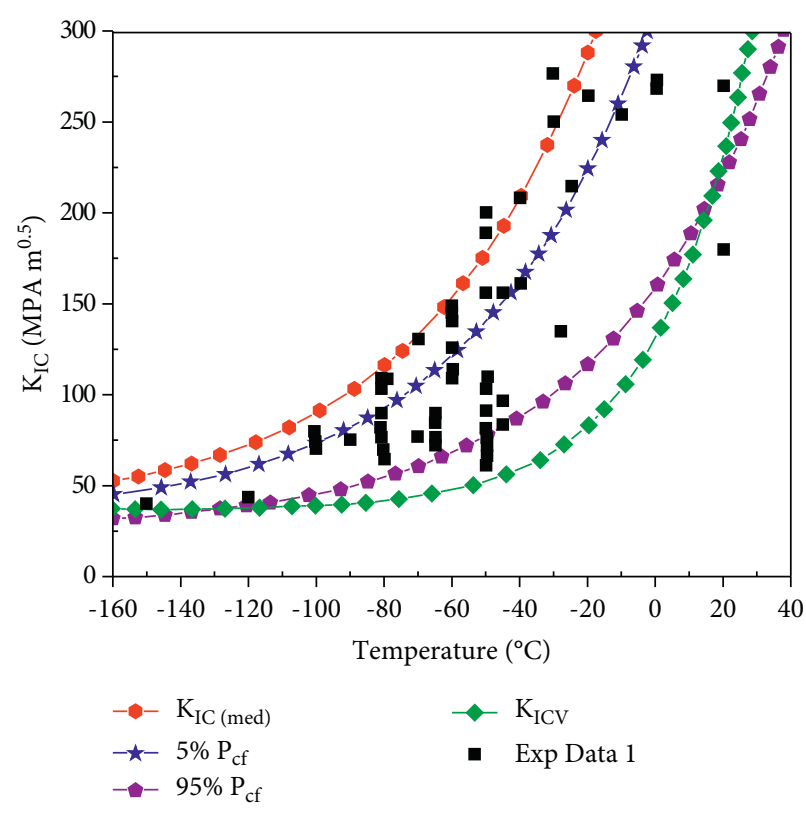

FIGURE 15: Fracture toughness curve generated by MC approach using fracture toughness Exp Data $1, T_{0}=-68.6^{\circ} \mathrm{C}$, and $5 \%$ and $95 \%$ RPV material failure probability.

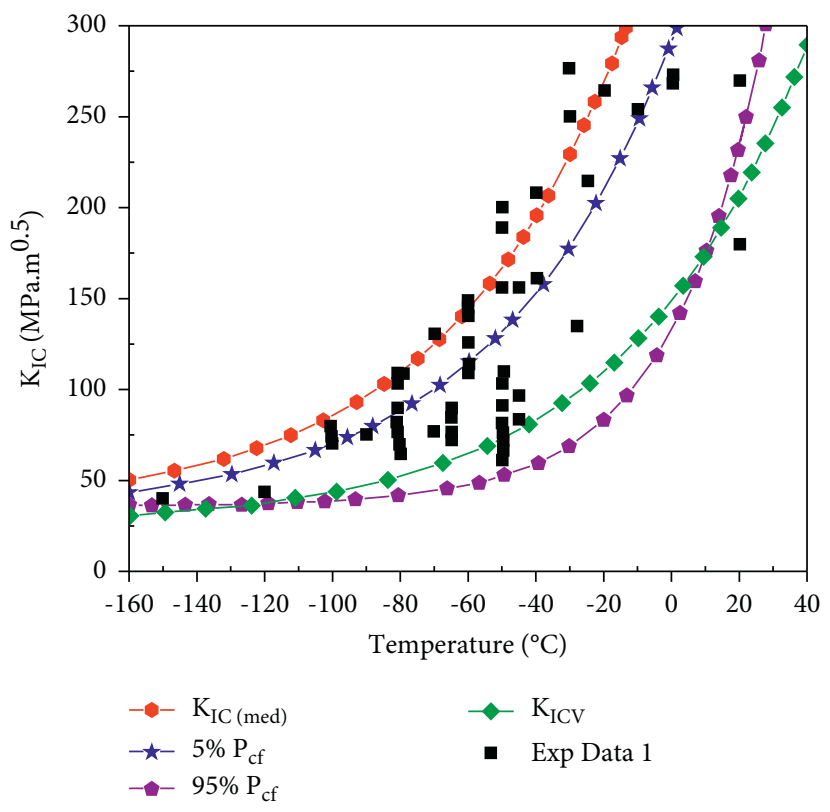

FIgURE 16: Fracture toughness curve generated by MC approach using fracture toughness Exp Data $1, T_{0}=-64.3^{\circ} \mathrm{C}$, and $5 \%$ and $95 \%$ RPV material failure probability.

elastic fracture resistance parameter $\left(K_{I C}\right)$ following the master curve approach, four experimental fracture toughness test data of the selected RPV steel material (Table 1) were collected from open literature (Figure 14). Two of the experimental fracture test data were then used to iteratively calculate $T_{0}$ based on the multitemperature method expressed in equation (8). This approach was applied to reduce the level of conservatism in computing $T_{0}$. The values of $T_{0}$ estimated based on Exp Data 1 and Exp Data 2 


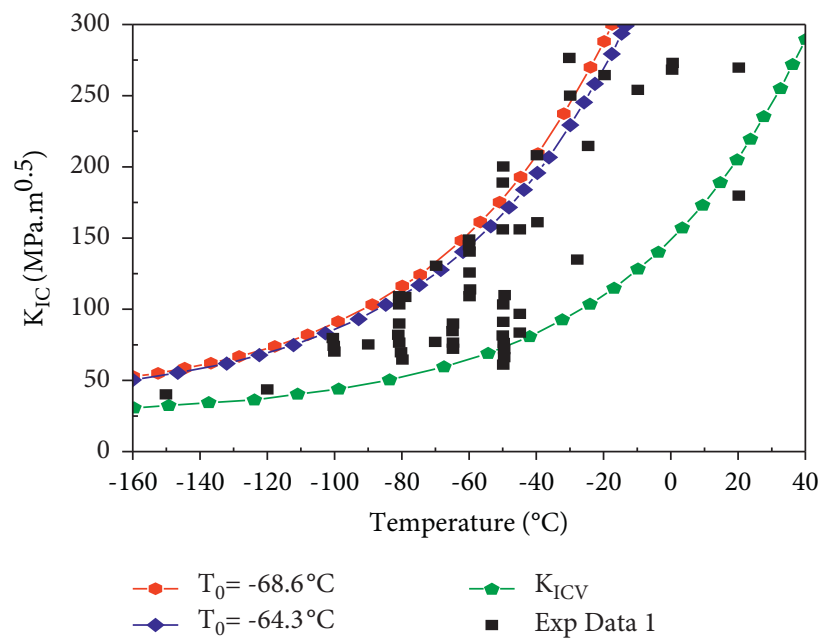

Figure 17: Comparison of two fracture toughness curves modeled by master curve method.

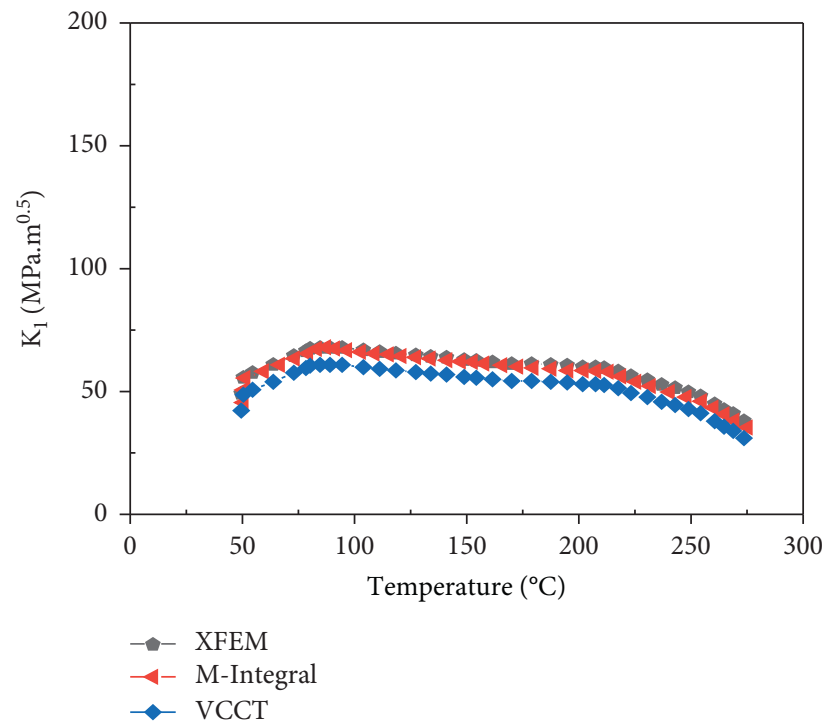

FIgURE 18: Comparison of $K_{I}$ modeled by M-Integral, XFEM, and VCCT methods at different crack tip temperatures.

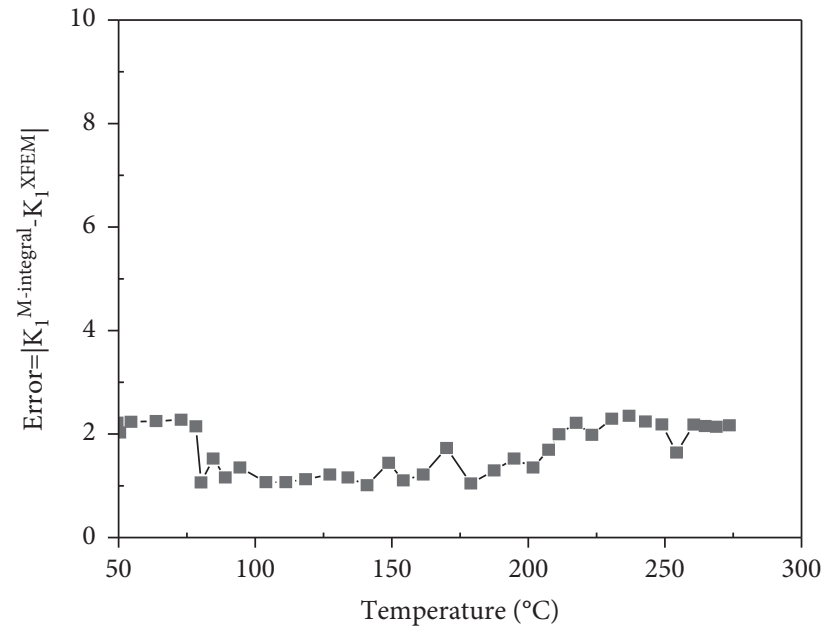

FIGURE 19: Error margin between the results of M-integral and XFEM $K_{I}$. 


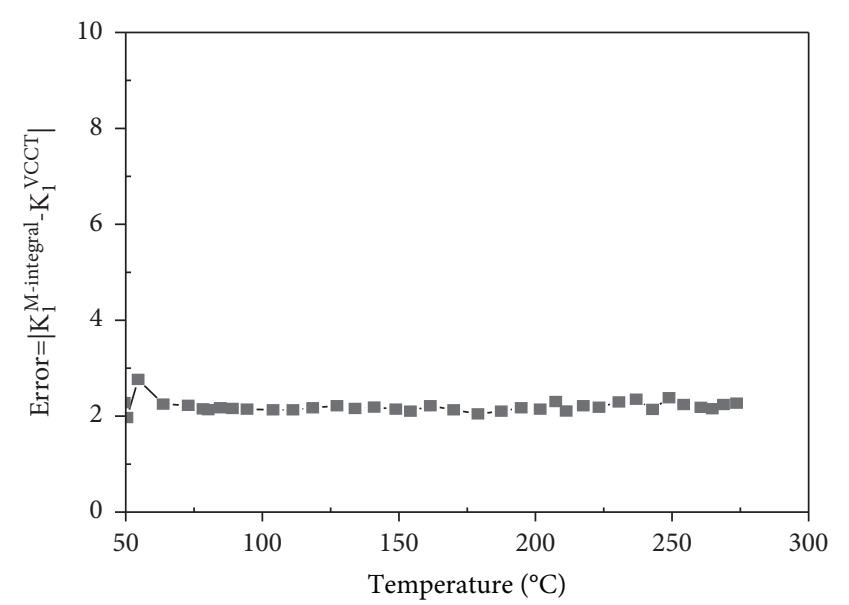

FIGURE 20: Error margin between the results of M-integral and VCCT $K_{I}$.

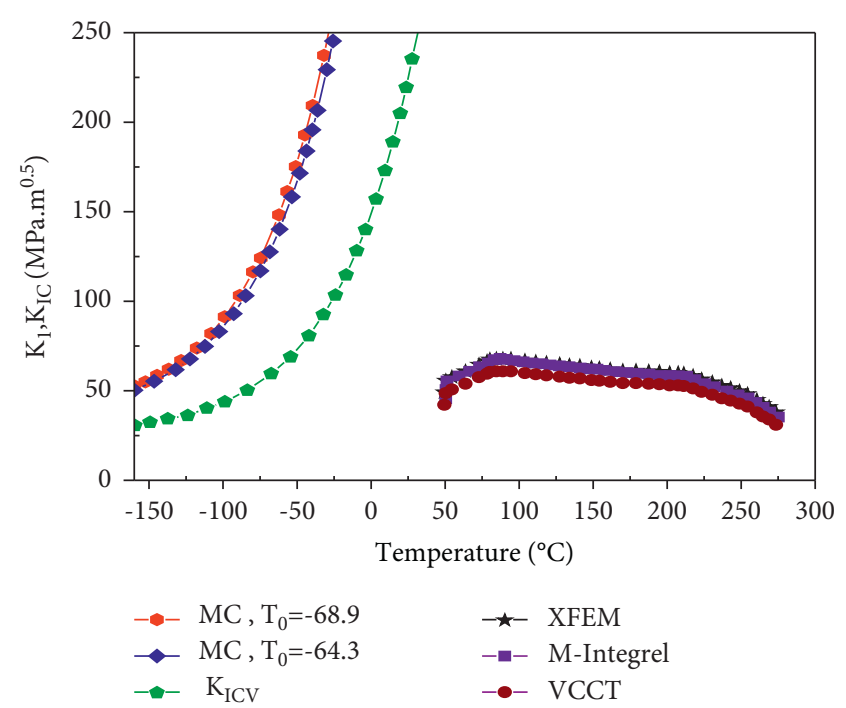

Figure 21: Comparison of $K_{I}$ with $K_{I C}$ at different crack tip temperatures.

(Figure 14) were $-68.6^{\circ} \mathrm{C}$ and $-64.3^{\circ} \mathrm{C}$, respectively. Figures 15 and 16 present the MC $\left(K_{I C(\text { med })}\right)$ and $5 \%$ and $95 \%$ probability of fracture failure based on the estimated $T_{0}$ values. Also, Figure 17 shows the comparison of the ASME fracture toughness curve $\left(K_{I C v}\right.$, equation (7)) and master curves generated in the transition temperature region based on $T_{0}$ values. $K_{I C v}$ adopted in this study was determined by Annor-Nyarko M. and Xia H., by assuming a neutron fluence of $4 \times 10^{19} \mathrm{n} / \mathrm{cm}^{2}$ at the end of life of the referenced two-loop PWR [5].

Figure 18 shows the comparison of $K_{I}$ at the deepest point of the postulated crack front with temperature computed by M-integral, VCCT, and XFEM approaches. The absolute errors of $K_{1}$ values estimated by the simplified multistep co-simulation based on M-integral and VCCT or XFEM are shown in Figures 19 and 20. The error margin of $K_{I}$ results presented shows that all approaches were in very good agreement, regardless of the different assumptions of each applied computational technique. The comparison of
$K_{I}$ and $K_{I C}$ plotted in Figure 21 shows the highest $K_{I}$ value estimated; $67.6 \mathrm{MPam}^{0.5}$ was less than both $\mathrm{MC} K_{I C}$ at $T_{0}=-68.9^{\circ} \mathrm{C}$ and $T_{0}=-64.3^{\circ} \mathrm{C}$ and ASME curve, $K_{I C v}$. In addition, the small values of $K_{I}$ obtained at the deepest crack tip were a result of the low compressive stresses generated by the PTS transient. In summary, results obtained from this study show that the PTS loads initiated by anticipated transient-inadvertent actuation of the SIS and the assumed axial surface crack orientation may not pose a significant thermomechanical change to the PWR RPV steel material. Therefore, the referenced RPV may have sufficient safety margin against the potential fracture failure associated with the frequent anticipated PTS transient.

\section{Conclusion}

Inadvertent actuation of the safety injection system is a critical anticipated transient that frequently occurs in the lifetime of PWRs. This anticipated transient induces PTS that may have an effect on the structural health of an ageing PWR's RPV; hence, it is important to estimate the RPV material's thermomechanical status under such asymmetric cyclic loads. In this paper, a simplified multistep analysis method comprising a direct thermomechanical analysis and a submodeling technique was used in the evaluation of the likely safety risk an ageing RPV may experience during an inadvertent actuation of an SIS incident. The following key conclusions can be made from this study:

(1) The applied direct thermomechanical FE method estimated the PTS thermal and internal pressure loadings simultaneously, as opposed to the sequential coupling method adopted in many studies. This is a simpler approach that reduces the computational costs and number of assumptions in the thermomechanical analysis of $3 \mathrm{D}$ complex geometries.

(2) The anticipated PTS transient generated the highest thermomechanical stress at the intersection between the inlet nozzle and inner vessel wall. This implies that the stress concentration area may be highly susceptible to the initiation of shallow cracks. In addition, the maximal stress though lower than the vessel's yield stress may cumulatively speed up the decrease in the ductility of an ageing RPV material.

(3) The $K_{I C}$ of the RPV material was estimated following the MC approach. The reference transition temperature of RPV material was evaluated using the ASTM standard E1921-05 multitemperature approach and experimental fracture toughness test data. This approach limited the overconservatism in $K_{I C}$ calculations.

(4) The critical parameter, $K_{I}$, at the deepest crack tip, estimated by the M-integral, VCCT, and XFEM methods were in good agreement. The absolute error margins were also within safety limits. 
(5) The $K_{\mathrm{I}}$ values from the PTS transient investigated compared to MC $\mathrm{K}_{\mathrm{IC}}$ show that induced stress may not cause a severe thermomechanical change in the PWR RPV steel over its service lifetime.

This study is essential for NPP decision-making on ageing and life management programmes for RPV. Future studies will focus on crack propagation and fatigue life prediction of ageing RPV with cladding material induced by anticipated operational PTS transients.

\section{Data Availability}

Data are available from the corresponding author upon request.

\section{Conflicts of Interest}

The authors declare that they have no conflicts of interest.

\section{Acknowledgments}

This work was supported by the National Natural Science Foundation of China (Grant no. 51379046), Natural Science Foundation of Heilongjiang Province (Grant no. E2017023), and the International Atomic Energy Agency (FS-INT1801254).

\section{References}

[1] G. R. Odette, T. Yamamoto, T. J. Williams, R. K. Nanstad, and C. A. English, "On the history and status of reactor pressure vessel steel ductile to brittle transition temperature shift prediction models," Journal of Nuclear Materials, vol. 526, Article ID 151863, 2019.

[2] P. Trampus, "Pressurized Thermal Shock analysis of the reactor pressure vessel," Procedia Structural Integrity, vol. 13, pp. 2083-2088, 2018.

[3] K. Thamaraiselvi and S. Vishnuvardhan, "Fracture studies on reactor pressure vessel subjected to pressurised thermal shock: a review," Nuclear Engineering and Design, vol. 360, Article ID 110471, 2020.

[4] S. Miranda, "Anticipated operational occurrences that could develop into serious accidents," Journal of Nuclear Engineering and Radiation Science, vol. 4, no. 2, pp. 020909-020914, 2018.

[5] M. Annor-Nyarko and H. Xia, "Integrity evaluation of a reactor pressure vessel based on a sequential abaqusFRANC3D simulation method," Science and Technology of Nuclear Installations, vol. 2021, pp. 1-12, 2021.

[6] USNRC, NRC Regulatory Issue Summary 2005-29 Anticipated Transient that Could Develop into More Serious Event, Office of Nuclear Reactor Regulation, Washington, WA, USA, 2005.

[7] R. Mukin, I. Clifford, H. Ferroukhi, and M. Niffenegger, "Pressurized thermal shock (Pts) transient scenarios screening analysis with trace," in Proceedings of the 26th International Conference on Nuclear Engineering, vol. 6a, London, UK, July 2018.

[8] T. Fekete, "The prospect of modern thermomechanics in structural integrity calculations of large-scale pressure vessels," Continuum Mechanics and Thermodynamics, vol. 30, no. 6, pp. 1267-1322, 2018.
[9] R. Chouhan, A. Kumar Kansal, N. Kumar Maheshwari, and A. Sharma, "Computational studies on pressurized thermal shock in reactor pressure vessel," Annals of Nuclear Energy, vol. 152, Article ID 107987, 2021.

[10] D. F. Mora, O. Costa Garrido, R. Mukin, and M. Niffenegger, "Fracture mechanics analyses of a reactor pressure vessel under non-uniform cooling with a combined TRACE-XFEM approach," Engineering Fracture Mechanics, vol. 238, Article ID 107258, 2020.

[11] D. F. Mora, M. Niffenegger, G. A. Qian, M. Jaros, and B. Niceno, "Modelling of reactor pressure vessel subjected to pressurized thermal shock using 3D-XFEM," Nuclear Engineering and Design, vol. 353, Article ID 110237, 2019.

[12] NEA/IAEA, "Nuclear power plant operating experiences," IAEA/NEA Incident Reporting System 2015-2017, International Atomic Energy Agency, Vienna, Austria, 2020.

[13] NEA/IAEA, Nuclear Power Plant Operating Experience from the IAEA/NEA International Reporting System for Operating Experience 2005-2008, International atomic energy agency, Vienna, Austria, 2010.

[14] IAEA, Pressurized Thermal Shock in Nuclear Power Plants: Good Practices for Assessment, International Atomic Energy Agency, Vienna, Austria, 2010.

[15] V. F. González-Albuixech, G. Qian, M. Sharabi, M. Niffenegger, B. Niceno, and N. Lafferty, "Integrity analysis of a reactor pressure vessel subjected to a realistic pressurized thermal shock considering the cooling plume and constraint effects," Engineering Fracture Mechanics, vol. 162, pp. 201-217, 2016.

[16] W. L. Server and R. K. Nanstad, "Integrity and embrittlement management of reactor pressure vessels (RPVs) in light-water reactors," in Irradiation Embrittlement of Reactor Pressure Vessels (RPVs) in Nuclear Power Plants, N. Soneda, Ed., Woodhead Publishing, Sawston, UK, pp. 132-155, 2015.

[17] AREVA, EPR Final Safety Analysis Report, USNRC, USA, 2013.

[18] M. Wang, Q. Zuo, H. Yu, W. Tian, G. H. Su, and S. Qiu, "Multiscale thermal hydraulic study under the inadvertent safety injection system operation scenario of typical pressurized water reactor," Science and Technology of Nuclear Installations, vol. 2017, Article ID 2960412, 15 pages, 2017.

[19] L. J. Young, "A fracture mechanics analysis of the PWR nuclear power plant reactor pressure vessel beltline weld," Journal of Nuclear Materials, vol. 288, no. 2-3, pp. 197-201, 2001.

[20] Altair, Altair HyperMesh, Altair Engineering Inc, Troy, MI, USA, 2014.

[21] M. Yu, Z. Luo, and Y. J. Chao, “An assessment of mechanical properties of a508-3 steel used in Chinese nuclear reactor vessels," Journal of Pressure Vessel Technology, vol. 137, no. 3, 2014.

[22] M. Niffenegger and K. Reichlin, "The proper use of thermal expansion coefficients in finite element calculations," Nuclear Engineering and Design, vol. 243, pp. 356-359, 2012.

[23] IAEA, "Guidelines for application of the master curve approach to reactor pressure vessel integrity in nuclear power plants," Technical Report, International Atomic Energy Agency, Vienna, Austria, 2005.

[24] M. F. Yu, Y. J. Chao, and Z. Luo, "Fracture toughness of Chinese nuclear reactor vessel steel a508-3 in the transition temperature region," Procedia Engineering, vol. 130, pp. 583-588, 2015. 
[25] IAEA, Master Curve Approach to Monitor Fracture Toughness of Reactor Pressure Vessels in Nuclear Power Plants, International Atomic Energy Agency, Vienna, Austria, 2009.

[26] K. Sun, X. Wu, G. Li, and B. Wen, "The fracture toughness properties of China manufactured reactor pressure vessel steels in transition temperature range," in Proceedings of the ASME 2018 Pressure Vessels and Piping Conference, p. 51678, Prague, Czech Republic, July 2018.

[27] Y. L. Zhang, H. Hui, J. B. Zhang, Z. Q. Zhou, X. Hu, and X. Cong, "Prediction of fracture toughness of SA738Gr.B steel in the ductile-brittle transition using master curve method and bimodal master curve method," International Journal of Pressure Vessels and Piping, vol. 182, Article ID 104033, 2020.

[28] IAEA, "Nuclear power plant operating experiences," IAEA/ NEA Incident Reporting System 1999-2002, International Atomic Energy Agency, Vienna, Austria, 2003.

[29] J. P. Holman, Heat Transfer, McGraw-Hill Companies, Inc, New York, NY, USA, Tenth. edition, 2010.

[30] H. Schlichting and K. Gersten, Boundary-Layer Theory, Springer-Verlag, Berlin, Germay, Ninth edition, 2017.

[31] M. Faheem, N. Ramzan, and S. Naveed, "STEAMEST: a software tool for estimation of physical properties of water and steam," Journal of Software, vol. 4, no. 3, pp. 226-231, 2009.

[32] W. Wagner and A. Kruse, Properties of Water and Steam/ Zustandsgrößen von Wasser und Wasserdampf, SpringerVerlag, Berlin, Germay, 1998.

[33] J. Mutava, M. Muvengei, K. Njoroge, and J. Kihiu, "Fracture mechanics approach to pressure vessel failures: a review," in Proceedings of the Sustainable Research and Innovation (SRI) Conference, Nairobi, Kenya, May 2015.

[34] IAEA, Guidelines on Pressurized Thermal Shock Analysis for WWER Nuclear Power Plants, International Atomic Energy Agency, Vienna, Austria, 2006.

[35] U. T. Murtaza, Optimization and Fracture Mechanics Analysis of the Set-In Nozzle of a PWR Reactor Pressure Vessel, Department of Mechanical Engineering, Pakistan Institute of Engineering and Applied Sciences, Nilore, Islamabad, Pakistan, 2016.

[36] P. A. Wawrzynek and B. J. Carter, The M-Integral for Computing Stress Intensity Factors in Generally Anisotropic Materials, National Aeronautics and Space Administration, Washington, WA, USA, 2005.

[37] V. F. González-Albuixech, G. Qian, and M. Niffenegger, "Integrity analysis of reactor pressure vessels subjected to pressurized thermal shocks by XFEM," Nuclear Engineering and Design, vol. 275, pp. 336-343, 2014.

[38] V. F. González-Albuixech, G. Qian, M. Sharabi, M. Niffenegger, B. Niceno, and N. Lafferty, "Comparison of PTS analyses of RPVs based on 3D-CFD and RELAP5," Nuclear Engineering and Design, vol. 291, pp. 168-178, 2015.

[39] Y.-P. Liu and T.-J. Li, "Application of the virtual crack closure technique (VCCT) using tetrahedral finite elements to calculate the stress intensity factor," Engineering Fracture Mechanics, vol. 253, Article ID 107853, 2021. 